\title{
Decreased Glucose Oxidation in Preterm Infants Fed a Formula Containing Medium-Chain Triglycerides
}

\author{
E. J. SUlKers, H. N. LAFEBER, J. B. van GOUdOEVER, S. C. KALHAN, \\ B. BEAUFRĖE, AND P. J. J. SAUER
}

\begin{abstract}
Erasmus University and Academic Hospital/Sophia Children's Hospital, Rotterdam, The Netherlands [E.J.S.,
II.N.L., J.B.V.G.. P.J.J.S.J: Case Western Reserve University, Rainbow Babies \& Childrens Hospital, Cleveland, Ohio 44106 [S.C.K.]; and Faculte de Médecine Alexis Carrel, Lyon, France [B.B.]
\end{abstract}

\begin{abstract}
Several formulas for preterm infants contain medium-chain triglycerides (MCT) to enhance fat absorption. Although fat absorption with MCT was slightly higher in several studies in preterm infants, a beneficial effect on growth has only been reported in one publication. We hypothesized that when part of the fat blend of preterm formula is substituted by MCT oil, this might lead to a different metabolic pattern in which, due to the preferential oxidation of MCT, an increase in lipogenesis from glucose could lead to an increase in metabolic rate. To study the impact of MCT on glucose metabolism, 18 preterm infants were randomized to receive either an MCT or an LCT formula containing 38- and 6\%-by-weight medium-chain fatty acids, respectively, in their fat blend. At 4 wk of age, the metabolic rate, substrate utilization, glucose kinetics, and oxidation were measured by indirect respiratory calorimetry in combination with a constant-rate oral infusion

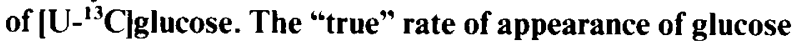
(Ra "true") was measured from the dilution of the uniformly labeled $(m+6)$ species of infused tracer, whereas "apparent" rate of appearance of glucose (Ra "apparent") was measured from the dilution of infused tracer $\mathrm{C}$ (carbon). The latter was measured by an on-line combustion method using a gas chromatograph-isotope ratio mass spectrometer. At a carbohydrate intake of $8.4 \mathrm{mg} \cdot \mathrm{kg}^{-1}$. $\mathrm{min}^{-1}$, total utilization of carbohydrate was equal in both groups at $7.6 \mathrm{mg} \cdot \mathrm{kg}^{-1} \cdot \mathrm{min}^{-1}$. However, glucose oxidation, as measured by the appearance of ${ }^{13} \mathrm{C}$ in breath $\mathrm{CO}_{2}$ was significantly lower in the MCT group $(4.5 \pm 0.83$ versus $5.7 \pm 0.67 \mathrm{mg} \cdot \mathrm{kg}^{-1} \cdot \mathrm{min}^{-1}$, MCT versus $\mathrm{LCT}$ ). Therefore, it can be assumed that a larger proportion of the glucose intake in the MCT group was used in the nonoxidative pathway, e.g. synthesis of fat as compared with the LCT group. There was no difference in the rate of endogenous glucose production and glucose $\mathrm{C}$ recycling between the two groups. In addition, the metabolic rate calculated from the rate of oxygen consumption was also similar $(59 \pm 5$ versus $62 \pm 4 \mathrm{kcal} \cdot \mathrm{kg}^{-1} \cdot \mathrm{d}^{-1}$, MCT versus $\mathrm{LCT}$ ). We conclude that, in preterm infants fed a formula containing $\mathbf{3 8} \% \mathrm{MCT}$ in their fat blend, glucose oxidation is significantly decreased whereas lipogenesis is probably increased. These findings may provide a mechanism for the so-called metabolic inefficiency of MCT. (Pediatr Res 33: 101-105, 1993)
\end{abstract}

Received March 19, 1992; accepted September 25, 1992.

Correspondence: Dr. E. J. Sulkers, c/o Prof. Dr. P. J. J. Sauer, Sophia Children's Hospital, Gordelweg 160,3038 GE Rotterdam. The Netherlands.

E. J. S. was supported by a grant from the Sophia Foundation for Scientific Research. S. C. K. was supported by NIH Grant HD1 1089.
Abbreviations

MCT, medium-chain triglyceride

LCT, long-chain triglyceride

$\mathrm{Ra}$, rate of appearance

The fat blend of several special formulas for preterm infants consists of $30 \%$ to $50 \%$ MCT to enhance fat absorption. In several studies in which MCT-containing fat blends were used in preterm infants, increased fat absorption without improved weight gain was reported (1-3); thus, one might expect that infants fed an MCT-containing formula either have an increased energy expenditure or lay down relatively more fat per $\mathrm{g}$ new tissue, resulting in a higher energy cost of growth. We hypothesized that an increased energy expenditure, which has been described before in animals and human adults during overfeeding with MCT (4-7), explains the lack of increase in growth rate at the higher energy absorption in preterm infants fed MCT formulas. We further speculated that an increased metabolic rate might result from an increased lipogenesis with ongoing fat oxidation, as MCT feeding is known to be associated with increased lipogenesis. In a previous study (8), using the same methods as in the present article, we showed a higher metabolic rate in parenterally fed infants receiving only glucose as their nonprotein energy source compared with infants receiving glucose and lipids. Moreover, we showed strong evidence that the higher metabolic rate was due to the conversion of glucose into fat, resulting in a lower food efficiency. To elucidate the mechanism of the apparently lower food efficiency in MCT feeding, we compared the effects on glucose metabolism and metabolic rate in two groups of very low birth weight infants fed formulas with different MCT content.

\section{PATIENTS AND METHODS}

Subjects. Eighteen infants with a birth weight of less than 1600 $\mathrm{g}$ were included in the study. Infants were eligible for inclusion if they were free from major metabolic problems and congenital malformations and if they were clinically stable and breathing room air at the introduction of oral feedings. At 1 wk of age, after permission was obtained from the parents, the infants were randomly assigned to receive either an MCT or an LCT formula, with nine infants entering each group. Enteral feedings were gradually introduced from $\mathrm{d} 7$ by continuous nasogastric tube feeding until a full intake of $150 \mathrm{~mL} \cdot \mathrm{kg}^{-1} \cdot \mathrm{d}^{-1}$ was reached. Both formulas were especially manufactured by Nutricia (Zoetermeer. The Netherlands) with a composition that was completely equal except for their fat blend. The batch of MCT formula in this 
study contained $38 \%$ medium-chain fatty acids derived from MCT oil, and the batch of LCT formula contained $6 \%$ derived from coconut oil. Both provided $8 \mathrm{~g}$ carbohydrates (lactose/ polycose 50/50), $2.2 \mathrm{~g}$ protein, and $6.8 \mathrm{~g}$ fat $/ 100 \mathrm{~mL}$ of prepared formula. Similar formulas are commercially available and recommended for preterm infants. One and the same batch from each formula was used during the study. The study was performed at least $3 \mathrm{~d}$ after the infant had received full oral feedings. The median day of study was 22 in the MCT and 24 in the LCT group; the total range was 19 to 37 . Patient characteristics and average intakes are described in Table 1 . The study protocol was approved by the medical ethical committee of the Erasmus University Academic Hospital/Sophia Childrens Hospital, Rotterdam, The Netherlands.

Methods. Indirect calorimetry. Metabolic rate and substrate utilization were measured in a closed-circuit indirect calorimeter. Continuous measurements were performed for 6 to $7 \mathrm{~h}$, as previously described in detail (9). During the study period, feeding was continued by a syringe pump at the same rate as during the $3 \mathrm{~d}$ before the study day. Urine was collected in plastic bags over periods of $3 \mathrm{~d}$. Urinary nitrogen concentration of a pooled sample was determined by combustion in an automatic nitrogen analyzer (ANA 1400 Carlo Erba, Milano, Italy).

Glucose oxidation study. During the calorimetry study, a stable isotope study was performed using uniformly labeled $\left[\mathrm{U}-{ }^{13} \mathrm{C}\right]$ glucose (Merck Isotopes, Montreal, Canada; $98.9 \%{ }^{13} \mathrm{C}$ ) to quantitate the oxidation of glucose.

To determine the natural background abundance of ${ }^{13} \mathrm{C}$ in expiratory air, three baseline breath samples were collected during $10 \mathrm{~min}$ each before starting the isotope infusion. The bicarbonate pool was then primed with $6.9 \mu \mathrm{mol} \cdot \mathrm{kg}^{-1}$ of a $6.9-\mathrm{mM}$ solution of $\mathrm{NaH}^{13} \mathrm{CO}_{3}(80 \%$ purity, Merck Isotopes) and a $\left[\mathrm{U}-{ }^{13} \mathrm{C}\right.$ ]glucose priming dose of $2.7 \mu \mathrm{mol} \cdot \mathrm{kg}^{-1}$ was given, followed by a constant infusion of $2.7 \mu \mathrm{mol} \cdot \mathrm{kg}^{-1}$ for 6 to $7 \mathrm{~h}$. All isotopes were administered through a separate nasogastric tube. Once the isotope infusion was started, $10-\mathrm{min} \mathrm{CO}_{2}$ breath collections were made every $\mathrm{h}$ for $4 \mathrm{~h}$, and every $15 \mathrm{~min}$ for 2 to 3 more $h$. Breath $\mathrm{CO}_{2}$ was collected by passing a sample of the air leaving the calorimeter through an all-glass spiral condenser, containing $10 \mathrm{~mL}$ of a fresh $1 \mathrm{M} \mathrm{NaOH}$ solution. Samples were transferred to Vacutainers (Becton Dickinson, Etten-Leur, The Netherlands) and stored at $-20^{\circ} \mathrm{C}$ until analysis. Trapping of $\mathrm{CO}_{2}$ was shown to be complete for at least $15 \mathrm{~min}$ at the sample flow used.

In a study conducted without the administration of isotopes, a shift in natural background over time was ruled out, as could be expected during a continuous feeding regimen.

Mass spectrometric analysis. Breath $\mathrm{CO}_{2}$. Respiratory $\mathrm{CO}_{2}$ trapped in $\mathrm{NaOH}$ was liberated at $<10^{-3}$ torr by adding $85 \%$ phosphoric acid to the $\mathrm{NaHCO}_{3}$ solution. $\mathrm{CO}_{2}$ was collected by cryogenic distillation and analyzed on a VG SIRA 10 isotope ratio mass spectrometer (Vacuum Generators, Winsford, Cheshire, UK). Results of ${ }^{13} \mathrm{C}$ abundance of both baseline and plateau were calculated as atom $\%$ excess/reference $\mathrm{CO}_{2}$ tank standard sample. Isotopic plateau during the final part of the study was confirmed by simple regression analysis on the last five data

Table 1. Patient characteristics

\begin{tabular}{lcc}
\hline & MCT & LCT \\
\hline Birth weight $(\mathrm{kg})$ & $1.2 \pm 0.24$ & $1.2 \pm 0.16$ \\
Gestational age $(\mathrm{wk})$ & $31 \pm 1$ & $32 \pm 2$ \\
Study weight $(\mathrm{kg})$ & $1.5 \pm 0.27$ & $1.6 \pm 0.21$ \\
Caloric intake $\left(\mathrm{kcal} \cdot \mathrm{kg}^{-1} \cdot \mathrm{d}^{-1}\right)$ & $126 \pm 3$ & $126 \pm 2$ \\
Carbohydrate intake $\left(\mathrm{mg} \cdot \mathrm{kg}^{-1}\right.$. & $8.4 \pm 0.21$ & $8.4 \pm 0.10$ \\
$\quad$ min & & \\
Fat intake $\left(\mathrm{mg} \cdot \mathrm{kg}^{-1} \cdot \mathrm{min}^{-1}\right)$ & $4.7 \pm 0.12$ & $4.7 \pm 0.06$ \\
Protein intake $\left(\mathrm{mg}^{-1} \mathrm{~kg}^{-1} \cdot \mathrm{min}^{-1}\right)$ & $2.3 \pm 0.06$ & $2.3 \pm 0.30$ \\
Weight gain $\left(\mathrm{g} \cdot \mathrm{kg}^{-1} \cdot \mathrm{d}^{-1}\right)$ & $16 \pm 4$ & $16 \pm 3$ \\
\hline
\end{tabular}

points. Figure 1 shows an example of the curves of enrichment obtained in expiratory $\mathrm{CO}_{2}$.

Blood glucose. Immediately before and after the study, blood was obtained by heel-stick from a warmed heel. After separation. plasma was stored at $-80^{\circ} \mathrm{C}$ for analysis of the isotopic enrichment of plasma glucose I) in uniformly labeled species, i.e. $(\mathrm{m}+6)$; and 2$)$ for the overall enrichment of glucose $\mathrm{C}$ by combustion using a gas chromatograph-isotope ratio mass spectrometer.

The $(m+6)$ enrichment of glucose was measured by chemical ionization gas chromatography mass spectrometry of the aldononitrile-pentacetate derivative of plasma glucose with selective ion monitoring of $\mathrm{m} / \mathrm{z} 328$ and 334 , as described before (11).

The ${ }^{13} \mathrm{C}$ enrichment of glucose $\mathrm{C}$ was also measured with a new technique, the on-line combustion using a gas chromatograph-isotope ratio mass spectrometer (Isochrom-I, Vacuum Generators) (12). With this technique, the effluent of the gas chromatograph, containing the same pentacetate derivative of plasma glucose, is combusted on-line in a catalytic furnace, and the resulting $\mathrm{CO}_{2}$ is driven by a helium flow into the ion source of a standard isotope ratio mass spectrometer after passing through a water trap. In this way, the tedious manual isolation of plasma glucose before combustion to $\mathrm{CO}_{2}$ necessary for the determination of ${ }^{13} \mathrm{C}$ enrichment of glucose as the precursor for glucose oxidation (13) is circumvented.

Calculations. Metabolic rate was calculated using the approach of Lusk (10), assuming an RQ of 1.00 for glucose and 0.72 for fat:

$$
\mathrm{np} \mathrm{VO}_{2}=\mathrm{VO}_{2}-(\mathrm{N} \times 6.25 \times 0.9663)
$$

where $\mathrm{np} \mathrm{VO}_{2}=$ nonprotein $\mathrm{O}_{2}$ consumption in $\mathrm{mL} \cdot \mathrm{kg}^{-1} \cdot \mathrm{min}^{-1}$, $\mathrm{VO}_{2}=$ total $\mathrm{O}_{2}$ consumption in $\mathrm{mL} \cdot \mathrm{kg}^{-1} \cdot \mathrm{min}^{-1}, \mathrm{~N}=$ urinary nitrogen in $\mathrm{mg} \cdot \mathrm{kg}^{-1} \cdot \mathrm{min}^{-1}$, and $0.9663=\mathrm{mL} \mathrm{O}_{2}$ consumed $/ \mathrm{mg}$ protein oxidized.

$$
n p R Q=\frac{\mathrm{VCO}_{2}-(\mathrm{N} \times 6.25 \times 0.7739)}{\mathrm{VO}_{2}-(\mathrm{N} \times 6.25 \times 0.9663)}
$$

where $\mathrm{VCO}_{2}=\mathrm{CO}_{2}$ production in $\mathrm{mL} \cdot \mathrm{kg}^{-1} \cdot \mathrm{min}^{-1}$ and 0.7739 $=\mathrm{mL} \mathrm{CO}$ produced $/ \mathrm{mg}$ protein oxidized.

$$
\begin{aligned}
\mathrm{MR}=1.44 & \times\left[4.702+\frac{\mathrm{np} \mathrm{RQ}-0.72)}{0.28} \times 0.345\right] \\
& \times \mathrm{np} \mathrm{VO}_{2}+\text { energy from protein oxidation }
\end{aligned}
$$

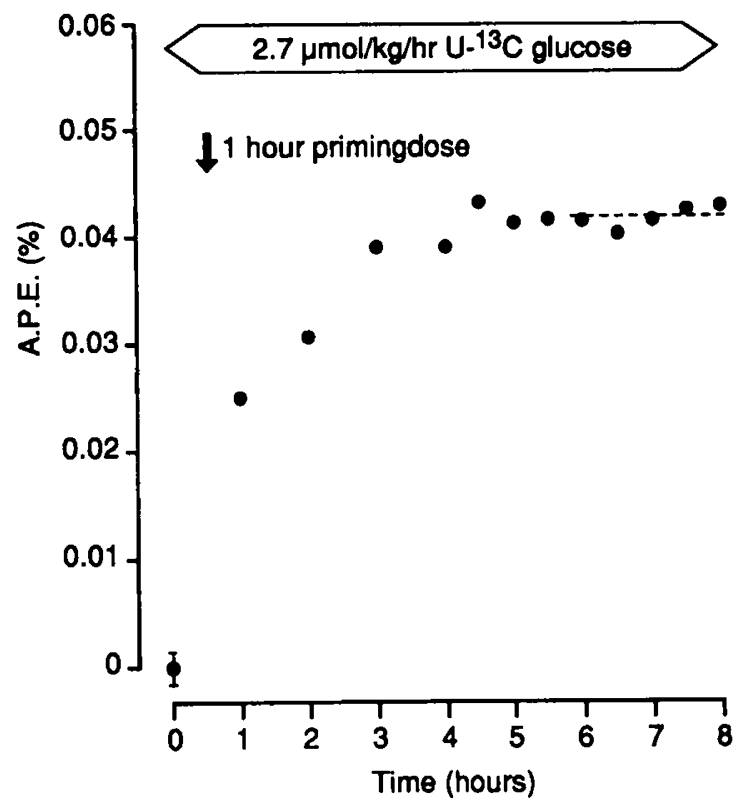

Fig. $1 .{ }^{13} \mathrm{CO}_{2}$ enrichment in expiratory air during a primed constant oral tracer infusion of $\left[\mathrm{U}^{13} \mathrm{C}\right] \mathrm{glucose}$ in one infant. 
where $\mathrm{MR}=$ metabolic rate $\left(\mathrm{kcal} \cdot \mathrm{kg}^{-1} \cdot \mathrm{d}^{-1}\right), 1.44=$ conversion factor for $\mathrm{mL} / \mathrm{min}$ to $\mathrm{L} / \mathrm{d}, 4.702$ = caloric equivalent of $1 \mathrm{~L} \mathrm{O}_{2}$ at a np RQ of 0.72 , and $0.345=$ difference between caloric equivalents of $1 \mathrm{~L} \mathrm{O}_{2}$ at np RQ of 1 and 0.72 .

The percentages of the $\mathrm{O}_{2}$ consumed by carbohydrate or fat are calculated according to the following formulas:

$$
\begin{gathered}
\text { \% Carbohydrate }=\frac{\mathrm{np} \mathrm{RQ}-0.72}{0.28} \\
\% \text { Fat }=\frac{1-\mathrm{np} \mathrm{RQ}}{0.28}
\end{gathered}
$$

The term carbohydrate utilization is used in accordance with Frayn (14), arguing that the rate of carbohydrate oxidation as measured with indirect calorimetry is the net result of glucose oxidation, lipogenesis from glucose, and gluconeogenesis from amino acids. At a high caloric intake when gluconeogenesis is low and lipogenesis can be high, the total carbohydrate "balance" or utilization as measured by indirect colorimetry is equal to the sum of the rate of true carbohydrate oxidation $\left(\mathrm{c}_{\mathrm{o}}\right)$ and the rate of conversion of carbohydrate to fat $\left(c_{f}\right)$, or $c=c_{o}+c_{f}$.

For this reason, the difference between carbohydrate utilization from indirect calorimetry and true carbohydrate oxidation measured independently, e.g. by isotopes, can give an indication of the rate at which the process of lipogenesis is occurring (8).

The fraction of infused tracer appearing in respiratory $\mathrm{CO}_{2}$ is calculated using the following formula:

$$
\text { Fraction of infused tracer } \mathrm{CO}_{2}=\frac{\mathrm{VCO}_{2} \times \mathrm{IE}_{\mathrm{CO} 2}}{0.989 \times \mathrm{F} \times 6 \times \mathrm{c}}
$$

where $\mathrm{VCO}_{2}$ is the rate of $\mathrm{CO}_{2}$ production, $\mathrm{IE}_{\mathrm{CO} 2}$ is the increase in isotopic enrichment of $\mathrm{CO}_{2}$ at plateau value, 0.989 is the infused tracer enrichment, $F$ is the tracer infusion rate, 6 is the number of $\mathrm{C}$ atoms/glucose molecule, and $\mathrm{c}$ is the correction factor for $\mathrm{CO}_{2}$ retention in the bicarbonate pool. Instead of taking a fixed fraction of 0.81 for $\mathrm{c}$, we calculated it individually according to the regression equation we described in an earlier publication (15):

$$
\mathrm{c}(\%)=64.2+\text { intake }\left(\mathrm{kcal} \cdot \mathrm{kg}^{-1} \cdot \mathrm{d}^{-1}\right) \times 0.1667
$$

The "true" Ra of glucose in the plasma pool was calculated from the dilution of the $(m+6)$ species of the labeled glucose.

$$
\text { Ra true }=\left[E_{i} / E_{p}-1\right] \times F
$$

where $E_{i}=(m+6)$ enrichment of infused tracer $=(0.989)^{6}$, $E_{p}=(m+6)$ enrichment of plasma glucose, and $F=$ rate of infusion of the tracer.

This is considered a measure of true $\mathrm{Ra}$ of glucose because the opportunity for a uniformly labeled $(m+6)$ species to recycle back via Cori cycle is considered to be negligible (16).

The "apparent" rate of glucose appearance in the blood was calculated from the enrichment of glucose $\mathrm{C}$ measured by the combustion method using the same dilution equation. In this case $E_{i}=0.989$, i.e. the ${ }^{13} \mathrm{C}$ enrichment of infused tracer, and $E_{p}=$ the ${ }^{13} \mathrm{C}$ enrichment of blood glucose $\mathrm{C}$. It should be recognized that ${ }^{13} \mathrm{C}$ enrichment of blood glucose $\mathrm{C}$ measured by the combustion method includes the recycled carbon and therefore will result in a lower rate of glucose appearance (Ra "apparent") as compared with the true Ra.

Glucose oxidation $=\mathrm{Ra}$ apparent

$$
\times \text { fraction of infused tracer in } \mathrm{CO}_{2} \text { (Eq. 1) }
$$

Glucose production was calculated by subtracting the glucose intake (calculated from the individual intakes of the continuously fed formula) from the rate of glucose appearance obtained by isotope dilution, $\mathrm{Ra}$ true. Glucose intake was calculated from the glucose part of lactose plus the glucose within the glucose polymers, assuming that there is complete intestinal hydrolysis and absorption of complex carbohydrates in preterm infants, as has been shown before (17). The galactose was not included in the glucose intake. If galactose is converted into glucose by the liver, it will be measured as glucose production upon release. The calculation also assumes there is no significant first-pass extraction of glucose in the splanchnic area of the (labeled) glucose. A validation study in five orally fed preterm infants was performed in which we measured $(m+6)$-glucose enrichment with both an oral and an i.v. tracer infusion protocol $2 \mathrm{~d}$ apart.

Figure 2 shows the enrichment in plasma obtained after infusion of $\left[\mathrm{U}-{ }^{13} \mathrm{C}\right]$ glucose in five orally fed preterm infants (represented by individual lines). The enrichment obtained by i.v. infusion would be expected to be higher than the enrichment obtained by oral infusion of tracer if there had been a significant amount of label retained in the liver, but in this case was $98 \pm$ $10 \%$ of the "oral enrichment." This result indicates that all (labeled) glucose passes the liver into the circulation, and no significant amount is being extracted on the first pass. These results are in accordance with studies in adults (18) showing an initial splanchnic extraction of glucose between 2.4 and $8 \%$.

$$
\text { Recycling }=\text { Ra true }- \text { Ra apparent }
$$

The recycling measured in this way is the amount of glucose recycled from three carbon intermediates like lactate through the Cori cycle, as discussed above.

Net glucose storage $=$ carbohydrate intake

$$
\text { - carbohydrate utilization from calorimetry }
$$

Statistics. Data are presented as mean \pm 1 SD. Differences between the MCT and the LCT group were tested using Wilcoxon's rank-sum (Mann-Whitney two-sample) test. A value of $p<0.05$ was considered to be statistically significant.

\section{RESULTS}

There were no significant differences between the two study groups in any of the parameters described in Table 1.

Results of the glucose studies are described in Table 2. Car-

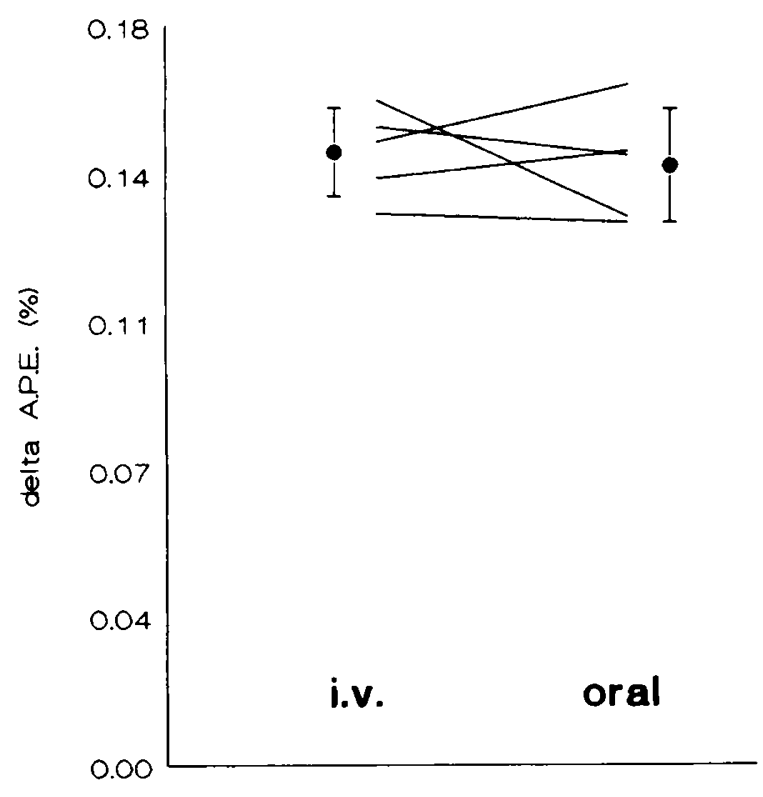

Tracer administration

Fig. 2. Increase in $(m+6)$-glucose enrichment after continuous infusion of $\left[\mathrm{U}-{ }^{13} \mathrm{C}\right] \mathrm{glucose}$ in five patients. Labeled glucose was infused i.v. on $1 \mathrm{~d}$ and orally $2 \mathrm{~d}$ later. Individual patients are indicated by individual lines, average enrichment oral is i.v. shows no trend toward one method (see text). 
Table 2. Glucose metabolism*

\begin{tabular}{|c|c|c|c|}
\hline & MCT & LCT & $p^{\dagger}$ \\
\hline \multicolumn{4}{|l|}{ Intake } \\
\hline Carbohydrate intake [1] & $8.4 \pm 0.21$ & $8.4 \pm 0.10$ & NS \\
\hline Glucose intake [2] & $6.3 \pm 0.16$ & $6.3 \pm 0.08$ & NS \\
\hline \multicolumn{4}{|l|}{ Calorimetry } \\
\hline Glucose utilization [3] & $7.5 \pm 0.96$ & $7.6 \pm 0.87$ & NS \\
\hline Fat utilization & $0.97 \pm 0.59$ & $1.24 \pm 0.53$ & NS \\
\hline $\begin{array}{l}\text { Metabolic rate }\left(\mathrm{kcal} \cdot \mathrm{kg}^{-1} \text {. }\right. \\
\left.\mathrm{d}^{-1}\right)\end{array}$ & $59 \pm 5$ & $62 \pm 4$ & NS \\
\hline \multicolumn{4}{|l|}{${ }^{13} \mathrm{C}$-glucose } \\
\hline Ra "true" [4] & $9.0 \pm 1.0$ & $9.0 \pm 0.83$ & NS \\
\hline Ra “apparent" [5] & $9.1 \pm 1.0$ & $8.7 \pm 0.90$ & NS \\
\hline Glucose oxidation [6] & $4.5 \pm 0.83$ & $5.7 \pm 0.67$ & $<0.01$ \\
\hline \multicolumn{4}{|l|}{ Calculated variables } \\
\hline Glucose production [4]-[2] & $2.79 \pm 0.90$ & $2.38 \pm 0.97$ & NS \\
\hline Recycling [4]-[5] & $-0.06 \pm 0.69 \ddagger$ & $0.25 \pm 0.83 \ddagger$ & NS \\
\hline Lipogenesis [3]-[6] & $3.0 \pm 1.3$ & $1.9 \pm 1.1$ & $<0.05$ \\
\hline Net storage [1]-[3] & $0.85 \pm 1.0 \S$ & $0.78 \pm 0.78 \S$ & NS \\
\hline
\end{tabular}

${ }^{*} \mathrm{mg} \cdot \mathrm{kg}^{-1} \cdot \mathrm{min}^{-1}$. Values between brackets are arbitrarily designated numbers. for use in the calculated variables.

+ NS, comparison between groups not significantly different from 0 . $<0.01$ or $<0.05$, comparison between groups significantly different from () at $p<0.01$ or 0.05 .

$¥$ Value in itself not significantly different from 0 .

$\S$ Value in itself significantly different from 0 at $p<0.05$.

bohydrate intake was equal at $8.4 \mathrm{mg} \cdot \mathrm{kg}^{-1} \cdot \mathrm{min}^{-1}$ in both groups, and carbohydrate utilization was $7.6 \mathrm{mg} \cdot \mathrm{kg}^{-1} \cdot \mathrm{min}^{-1}$ in both groups. In both groups, a small but significant amount of glucose was being stored, but this was not different between the two feeding groups. There were also no differences in fat utilization or metabolic rate as measured with indirect calorimetry. The $\mathrm{Ra}$ of glucose calculated in the two different ways used here yielded very similar results, and hence the difference between the two tracer methods-which is expected to represent recycling through three carbon fragments-was not different from zero. The glucose production was not significantly different between groups and not significantly different from the galactose intake, which was $2.1 \mathrm{mg} \cdot \mathrm{kg}^{-1} \cdot \mathrm{min}^{-1}$ in both groups.

A statistically significant difference between the two groups in glucose oxidation was observed: $4.5 \mathrm{mg} \cdot \mathrm{kg}^{-1} \cdot \mathrm{min}^{-1}$ in the MCT group versus 5.7 in the LCT group $(p<0.01)$. The difference between glucose oxidation measured with stable isotopes and total glucose utilization from calorimetry, as a measure of lipogenesis, was significantly higher in the MCT-fed group $[3.0$ versus $1.9 \mathrm{mg} \cdot \mathrm{kg}^{-1} \cdot \mathrm{min}^{-1}$ in the LCT group $\left.(p<0.05)\right]$.

\section{DISCUSSION}

Our initial hypothesis that MCT-fed infants would have a higher metabolic rate, to explain that their growth is often not higher even though their metabolizable energy intake is higher, could not be substantiated in this study.

In an earlier study, we showed that infants fed an MCTcontaining formula absorbed an extra amount of approximately $5-6 \mathrm{kcal} \cdot \mathrm{kg}^{-1} \cdot \mathrm{d}^{-1}$ of fat (19). A remarkable result in the present study was the decrease of $1.1 \mathrm{mg} \cdot \mathrm{kg}^{-1} \cdot \mathrm{min}^{-1}$ of glucose oxidation in the MCT group, which means a decrease of more than $6 \mathrm{kcal}$. $\mathrm{kg}^{-1} \cdot \mathrm{d}^{-1}$ in the energy derived from direct glucose oxidation. This strongly suggests that MCT very specifically decreases glucose oxidation in the well-fed preterm infant. In contrast with this, we found carbohydrate utilization from calorimetric data to be virtually identical.

Body stores of glycogen in adults can probably rise to a maximum of about $100 \mathrm{~g}(20)$, equivalent to an estimated maximum in the neonate of around $2 \mathrm{~g} \cdot \mathrm{kg}^{-1}$ total body stores. As the infants have been and are continuously fed high caloric feedings that provide $12 \mathrm{~g} \cdot \mathrm{kg}^{-1} \cdot \mathrm{d}^{-1}$ of carbohydrates. it can be expected that glycogen stores are filled. Galactose presented to the liver in that case cannot lead to net glycogen accretion. This is consistent with our finding that glucose production rate was not significantly different from the galactose intake. Also, in a recent publication (21), Spedale et al. have measured in vivo a preferential first-pass hepatic uptake for galactose and the absence of a net hepatic uptake of glucose in the postabsorptive newborn lamb, confirming the idea that galactose is taken up preferentially by the newborn lamb, with a net hepatic glucose output approximately equal to the galactose uptake in the postabsorptive state.

Glucose probably cannot be stored as glycogen to a significant extent after a period of continuous delivery of $120 \mathrm{kcal} \cdot \mathrm{kg} \cdot$ day as argued before, and it seems likely that the nonoxidized glucose will be shuttled into lipogenesis. The increased difference between stable isotope and calorimetric measurement of glucose metabolism in the MCT group also point at an increased rate of lipogenesis from glucose, as we have argued before $(8,22)$. Indirect calorimetry measures utilization of fat and carbohydrates where the amount converted ultimately into $\mathrm{CO}_{2}$ is the entity measured and the pathway taken does not influence the total stoichiometry. For instance, ketones formed from fat and consequently oxidized have the same effect on stoichiometry as direct fat oxidation, and carbohydrate conversion into fat with subsequent fat oxidation results in "measurement" as carbohydrate oxidation. Thus, in some states of excess energy supply where lipogenesis is occurring with ongoing fat oxidation, RQ might not rise above 1 (no net lipogenesis), but still, the carbohydrate utilization obtained by the calorimetric measurement overestimates the real glucose oxidation. As Frayn (14) showed that (in the absence of some other processes like ketogenesis with urinary loss of ketone bodies) calorimetry quantitatively overestimates glucose oxidation by the amount of glucose converted into fat, we can estimate from the significantly increased difference between the two techniques that an extra $1.1 \mathrm{mg} \cdot \mathrm{kg}^{-1}$. $\mathrm{min}^{-1}$ of glucose was converted into fat in the MCT group (Table 2 ). For the absolute amount of fat oxidized to be determined, an estimate should be made of what part of the difference between glucose oxidation and glucose utilization already existing in the LCT group was due to lipogenesis and what amount could be ascribed to other causes. One such cause would be the underestimation of glucose oxidation by the tracer technique due to intracellular oxidation of glycogen that did not enter the plasma pool and hence made no contribution to the measured glucose production (13). Although fairly confident about increased lipogenesis as the cause of the increased discrepancy between the two measurements of glucose metabolism in the comparison of MCT versus $\mathrm{LCT}$, we feel that it would be too speculative to suppose that the difference between stable isotopes and calorimetry can always be quantitatively converted into values for lipogenesis.

The finding in a recent study (23) of a significant difference between isotopically determined glucose oxidation and indirect calorimetry values during hyperinsulinemic euglycemia, but not during saline infusion, confirms the idea that both methods can yield identical results in the fasting state, whereas a difference attributable to lipogenesis is present during hyperinsulinemia.

In one study, most relevant to ours (13), the effect of elevated FFA levels on glucose oxidation was studied using the same two techniques as ours. It was concluded that FFA lowers carbohydrate utilization as measured with calorimetry, whereas plasma $\left[\mathrm{U}-{ }^{13} \mathrm{C}\right]$ glucose oxidation was not influenced. It was concluded that FFA probably lowered intracellular glycogen oxidation under those particular circumstances. Although there was no effect of FFA on plasma glucose oxidation in the latter study even though there was an additional caloric intake due to the infusion of an intravenous fat emulsion, in the present study $\left[\mathrm{U}-{ }^{13} \mathrm{C}\right]$ glucose oxidation was significantly decreased with isocaloric replacement of part of the LCT in the fat blend by MCT, again pointing at a very specific effect of MCT. The presence of carbons with chain lengths $<16$ is negligible in the fat emulsion used. 
and. to our knowledge. no reports have been published in the effect of MCT on isotopically measured glucose oxidation in vivo.

Apart from the original indication of fat malabsorption, MCT supplementation is currently being recommended for a variety of purposes (24), including seemingly contradictory objectives like (parenteral) hyperalimentation and obesity control. The literature does not definitively analyze the benefits of MCT administration. Moreover, all trials have been performed comparing MCT with LCT. In light of our study showing a more pronounced effect of MCT than LCT on plasma glucose oxidation, reconfirming the conclusion of the carbohydrate-like behavior of MCT as suggested $25 \mathrm{y}$ ago (25). it might be more realistic also to compare MCT administration to simply additional carbohydrates administration. Obviously, these considerations do not apply to specific indications like general malabsorption.

The overestimation of glucose oxidation obtained with calorimetry in our study shows that at least part of the lipogenesis with MCT feeding occurs from glucose in preterm infants on regular preterm MCT formula. In an earlier study, similar indirect evidence of increased lipogenesis was found to be associated with a decreased food efficiency (higher metabolic rate at equal energy intake) in the glucose-only parenteral feeding regimen (8). Although not confirmed in the present study, an increased metabolic rate during overfeeding with MCT has been described in animals and adult human volunteers (4-7). In these cases, the observed increase in metabolic rate has been ascribed either to ketogenesis (4), obligatory oxidation $(5,6)$, or lipogenesis from $\operatorname{MCT}(7)$.

In summary, we propose that the following metabolic picture can be derived from our results: In preterm infants receiving an energy intake of $120 \mathrm{kcal} \cdot \mathrm{kg}^{-1} \cdot \mathrm{d}^{-1}$ providing $8.4 \mathrm{mg} \cdot \mathrm{kg}^{-1} \cdot \mathrm{min}^{-1}$ carbohydrates, approximately $10 \%$ of the carbohydrate intake is stored or converted nonoxidatively in this period of rapid growth $\left(\approx 1.6 \% \cdot \mathrm{d}^{-1}\right)$. Another two thirds of the glucose in the LCT group is directly oxidized, whereas the remaining glucose is either reoxidized intracellularly coming directly from glycogen or converted to fat. When MCT is replacing part of the LCT fat in the diet. a significant decrease in the glucose oxidation is observed. but as carbohydrate balance is strictly regulated this does not show in the carbohydrate utilization measured with calorimetry. This observation indicates that the extra glucose not oxidized in the MCT group is probably converted into fat. which influences the calorimetric measurement and not the direct glucose oxidation measurement. In this way, an inefficient consequence of the supposed "obligatory oxidation" of MCT could exist, as lipogenesis occurs together with ongoing fat oxidation. However, in our study design, this did not lead to a higher total metabolic rate.

\section{REFERENCES}

1. Huston RK. Reynolds JW, Jensen C. Buist NR 1983 Nutrient and mineral retention and vitamin $\mathrm{D}$ absorption in low-birth-weight infants: effect of medium-chain triglycerides. Pediatrics 72:44-48
2. Okamoto E. Muttart CR. Zucker CL. Heird WC 1982 Use of medium-chain triglycerides in feeding the low-birth-weight infant. Am J Dis Child 136:428431

3. Tantibedhyangkul P. Hashim SA 1975 Medium-chain triglyceride feeding in premature infants; effects on fat and nitrogen absorption. Pediatrics 55:359370

4. Crozier G. Bois-Joyeux B. Chanez M. Girard J. Peret J 1987 Metabolic effects induced by long term feeding of medium-chain triglycerides in the rat. Metabolism 36:807-814

5. Baba N. Bracco EF. Hashim SA 1982 Enhanced thermogenesis and diminished deposition of fat in response to overfeeding with diet containing medium chain triglycerides. Am J Clin Nutr 35(4):678-682

6. Geliebter A. Torbay N. Bracco EF. Hashim SA. Van Itallic TB 1983 Overfeeding with medium-Chain triglyceride diet results in a diminished deposition of tat. Am J Clin Nutr 37:1-4

7. Hill JO, Peters, JC, Yang D. Sharp T, Kaler M. Abumrad NN, Greene HL 1989 Thermogenesis in humans during overfeeding with medium-chain triglycerides. Metabolism 38:641-648

8. Van Aerde JEE. Sauer PJJ, Pencharz PB. Smith JM. Swyer PR 1989 Effect of replacing glucose with lipid on the energy metabolism of newborn infants. Clin Sci 76.581-588

9. Sauer PJJ. Dane HJ. Visser HKA 1984 Longitudinal studies on metabolic rate. heat loss. and energy cost of growth in low birth weight infants. Pediatr Res 18:254-259

10. Lusk G 1924 Analysis of the oxidation of carbohydrate and fat. J Biol Chem $54: 41-42$

11. Kalhan SC, Ricanti ES, Tserng KY, Savin SM 1983 Glucose turnover in chronic uremia: increased recycling with diminished oxidation of glucose. Metabolism 32:1155-1162

12. Tissot S. Normand S, Guilluy R. Pachiaudi C. Beylot M. Laville M. Cohen R. Mornex R. Riou JP 1990 Use of a new gas chromatograph isotope ratio mass spectrometer to trade exogenous ${ }^{13} \mathrm{C}$ labeled glucose at a very low level of enrichment in man. Diabetologia 33:449-456

13. Wolfe BM. Klein S. Peters EJ. Schmidt BF. Wolfe RR 1988 Effect of elevated free fatty acids on glucose oxidation in normal humans. Metabolism 37:323329

14. Frayn KN 1983 Calculation of substrate oxidation rates in vivo from gaseous exchange. J Appl Phvsiol 55:628-6.34

15. Van Aerde JEE, Sauer PJJ, Penchar PB, Canagarayar U. Beesley J. Smith JM. Swyer PR 1985 The effect of energy intake and expenditure on the recovery of ${ }^{13} \mathrm{CO}_{2}$ in the neonate during a 4-hour primed constant infusion of $\mathrm{NaH}^{13} \mathrm{CO}_{3}$. Pediatr Res 19:806-810

16. Tserng K-Y. Kalhan SC 1983 Estimation of glucose carbon recycling and glucose turnover with $\left[\mathrm{U}^{13} \mathrm{C}\right] \mathrm{glucose}$. Am J Physiol 245:E476-482

17. De Curtis M. Senterre J. Rigo J. Putet G 1986 Carbohydrate derived energy and gross energy absorption in preterm infants fed human milk or formula. Arch Dis Child 61:867-870

18. Ferrannini E, Björkman O. Reichard Ga. Pilo A. Olsson M. Wahren $M$ DeFronzo RA 1985 The disposal of an oral glucose load in healthy subjects. Diabetes 34:580-588

19. Sulkers EJ. Goudoever JB v. Leunisse C, Wattimena JLD. Sauer PJJ 1992 Comparison of two preterm formulas with or without addition of mediumChain triglycerides (MCT). I: effects on nitrogen and fat balance and body composition changes. J Pediatr Gastroenterol Nutr 15:34-41

20. Björntorp P, Sjöström L 1978 Carbohydrate storage in man: speculations and some quantitative considerations. Metabolism 1853-1865

21. Spedale SB. Battaglia FC. Sparks JW 1992 Hepatic metabolism of glucose galactose, and lactate after milk feeding in newborn lambs. Am J Physio 262:E46-E5!

22. Sauer PJJ, Van Aerde J, Pencharz P. Swyer P 1986 Glucose oxidation rates in newborn infants measured with indirect calorimetry and $\left[\mathrm{U}^{13} \mathrm{C}\right] \mathrm{glucose}$. Clin Sci 70:587-593

23. McMahon MM. Marsh HM. Rizza RA 1991 Comparison of extracellular and net glucose oxidation measured isotopically and by indirect calorimetry during high and low glucose turnover. Am J Clin Nutr 53:1138-1142

24. Bach AC. Babavan VK 1982 Medium-chain triglycerides: an update. Am J Clin Nutr 36:950-962

25. Kuo PT. Huang NN 1965 The effect of medium chain triglyceride upon fat absorption and plasma lipid and depot fat of children with cystic fibrosis of the pancreas. J Clin Invest 44:1924-1933 